\title{
New three-dimensional/four-dimensional volume rendering imaging software for detecting the abnormally invasive placenta
}

\author{
Rozi Aditya Aryananda MD ${ }^{1}$ ( ) A Aldika Akbar MD ${ }^{1}$ | Manggala Pasca Wardhana MD ${ }^{1}$ | \\ Khanisyah Erza Gumilar MD ${ }^{1}$ | Budi Wicaksono MD ${ }^{1}$ | Ernawati Ernawati MD, $\mathrm{PhD}^{1}$ | \\ Agus Sulistyono $\mathrm{MD}, \mathrm{PhD}^{1}$ | Aditiawarman Aditiawarman $\mathrm{MD}, \mathrm{PhD}^{1}$ | \\ Hermanto Tri Joewono MD, PhD ${ }^{1}$ | Erry Gumilar Dachlan MD, PhD $^{1}$ | \\ Anupam Parange MD $^{2}$ | Gustaaf Albert Dekker MD, PhD, FRANZCOG, DCOG ${ }^{1,2}$
}

\begin{abstract}
${ }^{1}$ Maternal-Fetal Medicine, Department of Obstetric \& Gynecology, Dr. Soetomo

Hospital, Faculty of Medicine of Universitas Airlangga, Surabaya, Indonesia

${ }^{2}$ Women \& Childrens Division, Department of Obstetrics and Gynecology, Lyell McEwin Hospital, University of Adelaide, Adelaide, Australia

\section{Correspondence}

Rozi Aditya Aryananda, Maternal-Fetal

Medicine, Department of Obstetrics \&

Gynecology, Dr Soetomo Hospital, Faculty of

Medicine of Universitas Airlangga, Surabaya,

Indonesia.

Email: rozi.odi@gmail.com
\end{abstract}

\begin{abstract}
Objective: This study aimed to determine the role of three-dimensional (3D)/four-dimensional (4D) volume rendering ultrasound (VRU) in the diagnosis of abnormally invasive placenta (AIP). Materials and Methods: Twelve consecutive patients strongly suspected of having AIP on the basis of conventional ultrasound (US) and clinical history performed between September 2016 and December 2016 in the main tertiary referral hospital in Surabaya, East Java were included in this prospective observational study. A Samsung WS 80A Elite US scanner with a 3D/4D "crystal vue" and "realistic vue" volume rendering mode was used to establish the diagnosis of AIP and evaluate the site, and depth of placental invasion. The VRU images were compared with the intraoperative findings.

Results: Using this novel US technique, all cases of suspected AIP were subsequently confirmed during surgery. Importantly, the new US technique provided a correct diagnosis of the degree of invasion in 11 out of these 12 suspected AIP cases: $5 / 5$ for placenta percreta, $3 / 3$ for placenta increta, and 2/3 for placenta accreta; one patient was misdiagnosed in terms of the degree of placenta accreta, and one patient had normal implantation).

Conclusion: This new software of 3D/4D VRU represents a promising technique for the preoperative diagnosis and staging of AIP.
\end{abstract}

\section{KEYWORDS}

3D/4D ultrasound, abnormally invasive placenta, obstetrics

\section{1 | INTRODUCTION}

Abnormally invasive placenta (AIP) or morbidly adherent placenta, which includes placenta accreta, placenta increta, and placenta percreta, is associated with substantial maternal and fetal morbidity and mortality. ${ }^{1}$

The global incidence of AIP has increased dramatically, primarily caused by the worldwide increasing rates of cesarean sections. Belfort ${ }^{2}$ reported that the incidence of AIP in the United States of
America has increased from approximately 0.8 per 1000 deliveries in the 1980 s to 3 per 1000 deliveries over the past decade.

Ultrasonography is used to evaluate placental position and implantation. Several scores have been proposed to detect AIP using US. Jauniaux et $\mathrm{al}^{3}$ completed a systematic review analyzing various prenatal US findings with grading's of AIP. A loss of the clear zone (62.1\%) and the presence of bridging vessels (71.4\%) were reported as the most common US findings in the case of placenta accreta. In placenta increta, a loss of the clear zone (84.6\%) and subplacental 
hypervascularity (60\%) have been reported as the most common US signs; the presence of placental lacunae (82.4\%) and subplacental hypervascularity (54.5\%) have been reported as the most common US signs in placenta percreta. ${ }^{3}$ The loss of the clear zone had a detection rate of approximately $93 \%$ (sensitivity $52 \%$ and specificity $57 \%$ ), and this marker had a high negative predictive value, ranging from $96 \%$ to $100 \% .{ }^{4,5}$ Color Doppler can be used as an adjunct to two-dimensional (2D) US in the diagnosis of AIP, with a sensitivity between $86 \%$ and $100 \%$ and specificity between $92 \%$ and $94 \% .^{6,7}$ The predictive value of lacunae varied by study, with a range of sensitivity between $73 \%$ and $100 \%$ and negative predictive value of $88 \%-100 \%^{8}$; when multiple lacunae are seen, especially four or more, the association with placenta accreta has been reported as $100 \%$ in some studies. ${ }^{4,9}$ Although these various US findings are helpful, no US sign or a combination of US signs has been found to be clinically accurate in determining the depth of invasion in individual AIP patients. ${ }^{3}$

All degrees of placental invasion may occur with AIP. Determining the degree and extent of placental invasion is critical for preoperative surgical planning (uterine conservative surgery vs cesarean hysterectomy, need for urologist involvement, etc). MRI has been used to predict the depth of AIP invasion, but it is expensive and often not immediately available. ${ }^{10}$

To date, it has not been clear whether or not three-dimensional (3D) US could truly help the clinician to arrive at an accurate diagnosis of AIP and in particular to provide detailed pre-operative insights regarding individual pathological anatomy. In contrast to MRI, viewing planes can be more easily manipulated to enhance visualization of the vascular framework of the placenta and adjacent tissues, thus potentially improving the detection of bladder and parametrial extensions. Four-dimensional US has the additional major advantage of allowing real time examination. ${ }^{11}$

At our tertiary care hospital in East Java (population of approximately 38 million in 2015), the incidence of AIP has reached $2 \%$ of all deliveries.

The aim of this study was to determine the role of $3 \mathrm{D} /$ fourdimensional (4D) volume rendering ultrasound (VRU) in the diagnosis of AIP and to correlate the US findings with the final intraoperative diagnosis.

\section{2 | METHODS}

This study was a prospective observational study performed between September 2016 and December 2016 in an Indonesian tertiary referral hospital. The placenta accreta index (PAI) ${ }^{12}$ was used, which combines the presence of retroplacental clear zone, bladder line, vesicouterine hypervascularity, and placental bulge to adjacent tissue was used to diagnose suspected AIP.

A Samsung WS 80A Elite US scanner with 3D/4D VRU software was used to assess the size and depth of the AIP. Two modes ("crystal vue" and "realistic vue") of the new software are available to preserve context and surface information. VRU visualizes interior and exterior structures while preserving clear shapes. According to intensity, VRU classifies each boundary and selectively displays necessary information to make the context of the structure visible. VRU can differentiate between subtle artifacts and real structures/lesions with automatic optimized settings in complex situations.

Trans-abdominal VRU was performed on a patient with a full bladder $(300-500 \mathrm{cc})$. The parameters used were as follows: gain 50-55 dB, dynamic range 100-105, frame average 7-10, and PRF scale 2.0-2.7 kHz. The preset default volume rendering $(12 \times 6 \mathrm{~cm})$ and scan angle $\left(65^{\circ}\right)$ provided a detailed focus of the placental/uterine interface and a clear 3D/4D image of the lesions. After the area suspected of AIP in the 3D/4D image was found, dual screen imaging was selected (sagittal and 3D/4D imaging) and the "crystal vue" and "realistic vue" VRU modes were used. Rotating the $Z$ axis panel was set to $90^{\circ}$ from the $Y$ axis so that the uterine wall and bladder wall would be clearly visible as two parallel lines.

The examination was done of the entire surface of the uterine low segment. The image analysis was performed after freeze mode on each uterine side of the 3D/4D examination. All image was set directly in the US machine after volume dataset was obtained.

The confirmation of AIP was done during surgery performed by the Maternal-Fetal Medicine staff. The surgeons did not perform the US examinations.

\section{3 | RESULTS}

Twelve patients with a very high ( $>50 \%$ ) suspicion of AIP were scanned using the VRU technique. The median age of the patients was approximately 33 year (23-39 year), and the median gestational age at the time of first US in our hospital was 36 weeks (32-37 weeks), reflecting the often very late referral of these patients.

VRU provided an accurate preoperative diagnosis in 11/12 patients (Table 1). One patient was underdiagnosed (intraoperative findings of increta vs VRU diagnosis of accreta) because of a lack of the retroplacental clear zone in the lower part of the uterus (Figure 1A,B), and the placental invasion was in the upper part of the vesicouterine pouch during surgery with supra vaginal hysterectomy (Figure $1 \mathrm{C}$ ).

The use of VRU allowed clear imaging of the retroplacental clear zone (Figure 2A), uterine wall and bladder wall as US characteristics of normal placentation (Figure $2 \mathrm{~B}$ ).

Cases of placenta accreta (Figure 3A): Placenta accreta can be diagnosed with the retroplacental clear zone still being detectable but very thin in VRU examination. The three patients with confirmed placental accreta were all correctly diagnosed using the VRU examination (Figure 3B) with PAI probability of invasion 51\%-69\%.

Placental increta: Placenta increta can be diagnosed on the basis of a loss of the retroplacental clear zone with uterine wall disturbance or an absence of the retroplacental clear zone only in VRU examination. Three patients had a PAI of $69 \%$, and these 3 patients had vesicouterine bridging vessels on the color Doppler US (Figure 4A). The 3 patients were correctly diagnosed as having placenta increta on VRU (Figure 4B), as confirmed during surgery (Figure 4C).

Placental percreta: placenta percreta can be diagnosed with discontinuity of the uterine wall and an interruption of the bladder wall, as well as an absence of the retroplacental clear zone due to infiltration by the placenta in VRU examination. Five patients had a vesicouterine bridging vessels on color Doppler (Figure 5A). According to the 
TABLE 1 The ultrasound parameter, VRU, and placental invasion from surgical examination result

\begin{tabular}{|c|c|c|c|c|c|c|c|c|c|}
\hline Patient number & Age & $\begin{array}{l}\text { GA } \\
\text { (wk) }\end{array}$ & $\begin{array}{l}\text { Previous } \\
\text { CS }\end{array}$ & $\begin{array}{l}\text { Retro-placental } \\
\text { clear zone }\end{array}$ & $\begin{array}{l}\text { Bladder line } \\
\text { Interuption }\end{array}$ & $\begin{array}{l}\text { Probability } \\
\text { of AIP }(\%)^{12}\end{array}$ & $\begin{array}{l}\text { Vesico-uterine } \\
\text { bridging vessel }\end{array}$ & VRU result & $\begin{array}{l}\text { Result from } \\
\text { surgery }\end{array}$ \\
\hline 2 & 32 & 32 & 2 & $(-)$ & $(+)$ & 96 & $(+)$ & Percreta & Percreta \\
\hline 4 & 33 & 35 & 2 & $(-)$ & $(-)$ & 69 & $(+)$ & Percreta & Percreta \\
\hline 5 & 37 & 32 & 2 & $(-)$ & $(+)$ & 96 & $(+)$ & Percreta & Percreta \\
\hline 7 & 38 & 35 & 1 & $(-)$ & $(-)$ & 69 & $(+)$ & Percreta & Percreta \\
\hline 8 & 34 & 37 & 1 & $(-)$ & $(-)$ & 69 & $(+)$ & Increta & Increta \\
\hline 9 & 39 & 37 & 1 & $(-)$ & $(-)$ & 69 & $(+)$ & Increta & Increta \\
\hline 10 & 34 & 36 & 2 & $(-)$ & $(-)$ & 51 & $(-)$ & Accreta & Accreta \\
\hline 11 & 33 & 38 & 2 & $(+)$ & $(-)$ & 69 & $(+)$ & Accreta & Increta \\
\hline
\end{tabular}

Abbreviations: GA, gestational age (wk); CS, Cesarean section; PAI, placenta accreta index; VRU, volume rendering ultrasound.

PAl, one patient had $96 \%$ and two patients had a $69 \%$ probability of placental invasion. All VRU-diagnosed cases of placenta percreta (Figure 5B) were confirmed during surgery (Figure $5 \mathrm{C}$ ). One of five patient had doubtful of placenta percreta in 2D US (Figure 6A), but VRU shows placenta percreta (Figure 6B) that confirmed during surgery (Figure 6C).

One patient with a high PAl score had an area with irregular pattern on color Doppler US that is usually found in high-grade AIP. While this patient had an absent retroplacental clear zone in 2D US (Figure 7A), and what appeared to be the presence of vesicouterine bridging vessel on color Doppler examination (Figure 7B), the VRU scanning indicated that this was most likely a false-positive diagnosis, as the uterine and bladder wall were still intact on VRU examination (Figure 7C). This was subsequently confirmed during surgery (Figure 7D). This outcome illustrates that VRU examination can distinguish between uterine-bladder wall with uterine varicose and high-grade AIP.

By identifying true bridging vessels, and providing superior imaging of the retroplacental clear zone, our preliminary results indicate that VRU may improve the diagnosis of AIP. One limitation of VRU is that it takes approximately 40 minutes for the first examination. With increasing experience, the scanning time has decreased to 5-10 minutes.
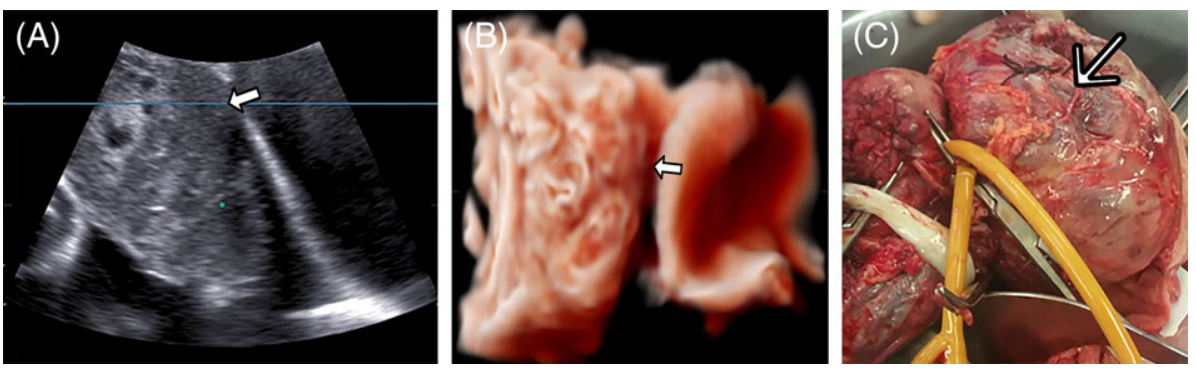

FIGURE 1 A, Absent of retroplacental clear zone $(\Rightarrow)$ in 2D US. B, Lack of retroplacental clear zone $(\Rightarrow)$ in 3D VRU shows placenta accreta invasion. C, Supra vaginal hysterectomy was performed and placenta increta was shown in the upper of vesicouterine pouch $(\rightarrow)$ during surgery
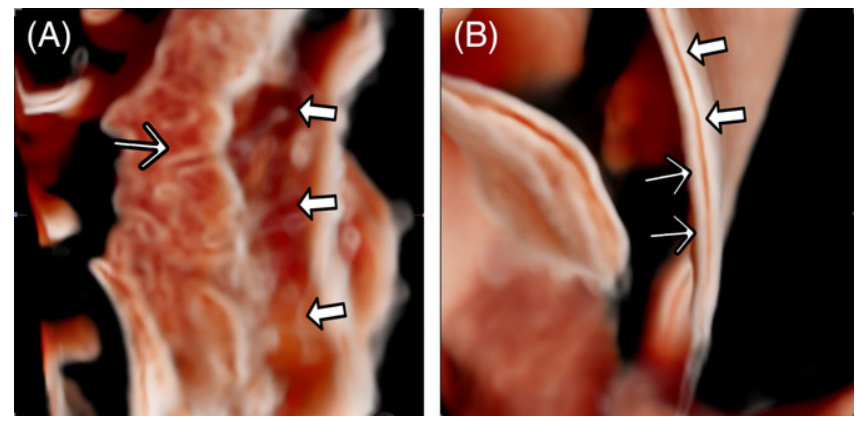

FIGURE 2 A, Retroplacental clear zone $(\Rightarrow)$ in 3D VRU in normal placental implantation $(\rightarrow)$. B, Uterine wall $(\rightarrow)$ and bladder wall $(\Rightarrow)$ form as two parallel line
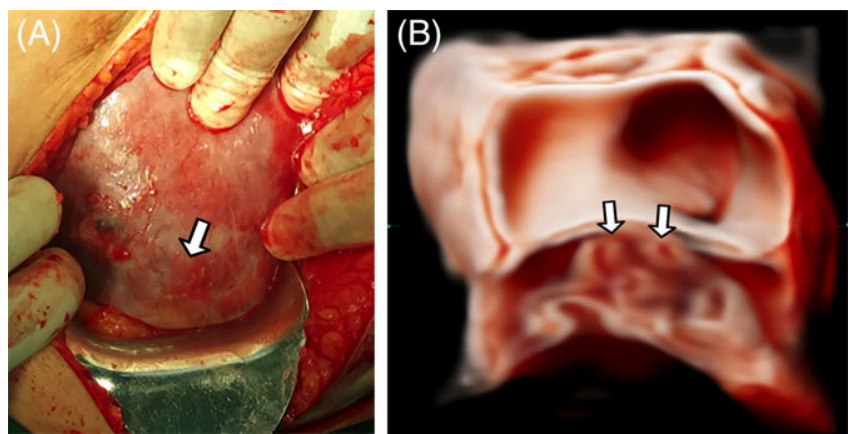

FIGURE 3 A, Surgical diagnosis of placenta accreta invasion $(\Rightarrow)$. B, Placental invasion of placenta accreta in 3D VRU $(\Rightarrow)$ 

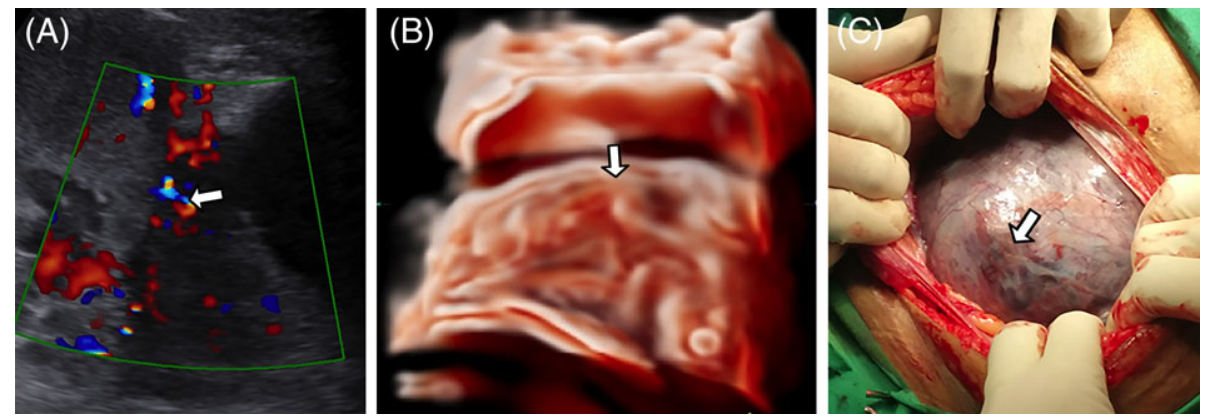

FIGURE 4 A, Vesicouterine bridging vessel in color Doppler US of placenta increta $(\Rightarrow)$. B, Three-dimensional VRU shows absent of retroplacental clear zone and uterine wall irregularity $(\Rightarrow)$. C, Surgical diagnosis of placenta increta $(\Rightarrow)$
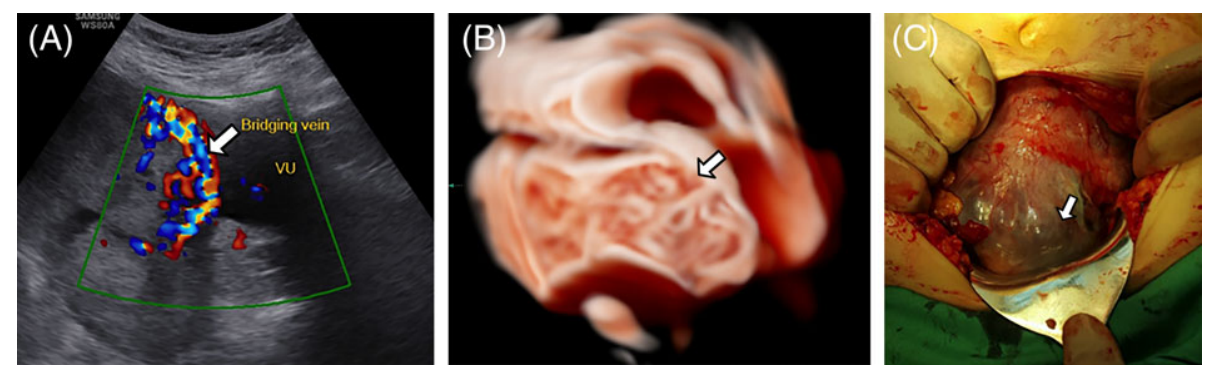

FIGURE 5 A, Vesicouterine bridging vessel in color Doppler US of placenta percreta $(\Rightarrow)$. B, Discontinuity of uterine wall in 3D VRU $(\Rightarrow)$. C, Placenta percreta was diagnosed during surgery $(\Rightarrow)$
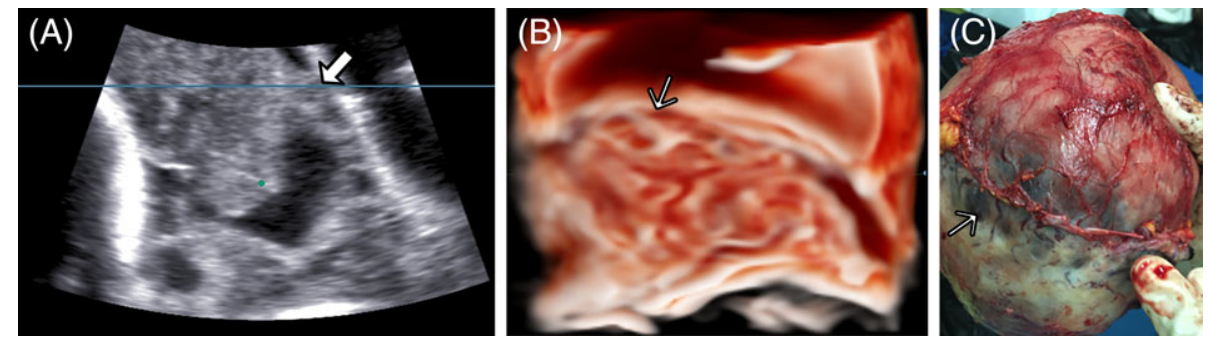

FIGURE 6 A, 2D US shows placenta accreta invasion in doubtful case $(\Rightarrow)$. B, Three-dimensional VRU shows discontinuity of uterine wall $(\rightarrow)$. C, Placenta percreta invasion was diagnosed during surgery $(\rightarrow)$
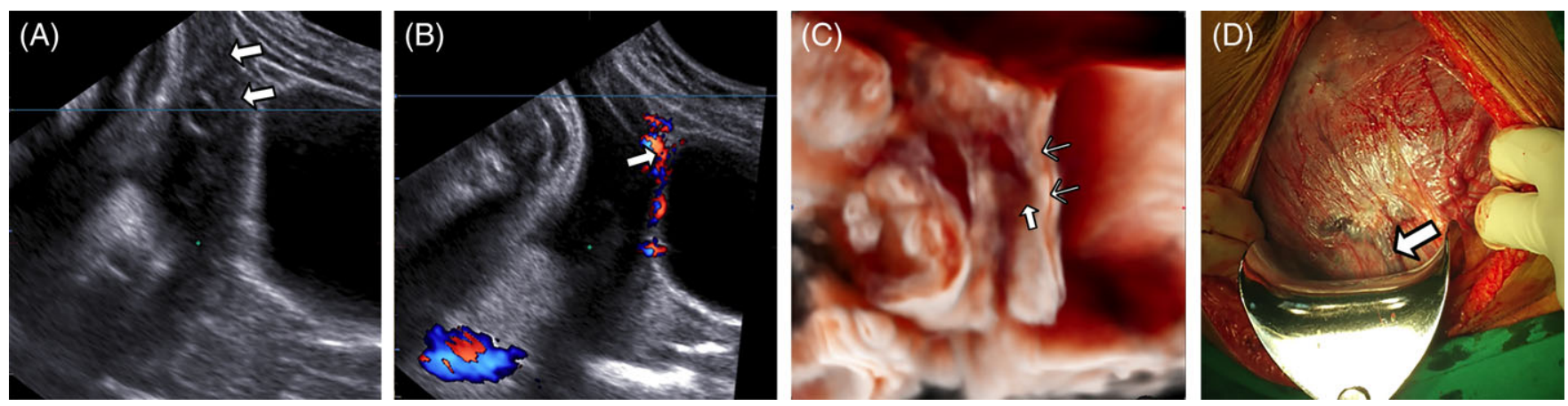

FIGURE 7 A, Absent of retroplacental clear zone during 2D US $(\Rightarrow)$. B, Vesicouterine bridging vessel $(\Rightarrow)$ in 2D Doppler US. C, Three-dimensional VRU shows intact uterine wall $(\rightarrow)$ and loss of retroplacental clear zone $(\Rightarrow)$ detection. D, Surgical examination shows low segment uterine varicose $(\Rightarrow)$ and low segment cesarean section was performed in this patient

\section{4 | DISCUSSION}

With the rapid increase in the rate of patients presenting with suspected AIP, several new imaging techniques, for example, MRI and US scoring systems, have been proposed to help the obstetrician to obtain an accurate pre-operative diagnosis of AIP. Accurate information regarding the size, location and depth of the invasion is of pivotal importance in planning the required surgical approach. Conventional US clearly has its limitations in diagnosing the depth of invasion. The PAl is easy to apply and has a high positive predictive value (PPV) and 
specificity if the score is high. ${ }^{12}$ In addition, the presence of so-called vesicouterine bridging vessels using color Doppler US has been reported to have a sensitivity of $90.7 \%$ and a specificity of $96.9 \%{ }^{1}$

Some findings on 2D US can be used with VRU. The absence of a clear retroplacental clear zone has a high sensitivity but a low specificity. Its primary diagnostic value is that its presence effectively excludes placenta accreta, with a high negative predictive value. ${ }^{4,5}$ Almost no patient included in this study had a retroplacental clear zone on 2D US, but VRU allowed further evaluation of this area. The bladder line has high specificity and PPV in diagnosed AIP. ${ }^{4}$ We had one case with a doubtful bladder line image on 2D US (Figure 6A). Importantly, VRU was able to show a protruded placenta (Figure 6B), suggesting that VRU can evaluate placental invasion in myometrium and bladder wall.

MRI may be the best modality for diagnosing placenta percreta, ${ }^{10}$ but the main limitations of this modality are its high costs and potential issues with a lack of access on a $24 / 7$ basis. The PAl is useful in clinical practice and helps to approach the various US findings in a more systematic way. However, it can only be used in patients with prior caesarean section(s), since having had one or more prior caesarean sections is an integral part of this score. Importantly, in our series, we encountered three cases with AIP after only one caesarean section. These patients would score lower using the PAI approach. High degrees of AIP are sometimes characterized by the presence of a rich vascular anastomotic system involving the bladder, uterus, and vagina, ${ }^{13}$ but this method has false positives in the presence of uterine varicosities.

VRU using "crystal vue" and "realistic vue" is a new technique based on image-contrast enhancement that can be used for processing and rendering of acquired $3 \mathrm{D}$ volumes. According to a study by Dall'Asta et al, ${ }^{14}$ this VRU software may offer new opportunities for prenatal imaging of the skeletal system and also of soft tissues. Based on our findings, we would like to conclude that this new imaging technique also appears to be a promising technique for the preoperative diagnosis and staging of AIP.

\section{ORCID}

Rozi Aditya Aryananda (D) http://orcid.org/0000-0001-6674-7682

\section{REFERENCES}

1. Gielchinsky Y, Rojansky N, Fasouliotis SJ, Ezra Y. Placenta Accreta-summary of 10 years: a survey of 310 cases. Placenta. 2002; 23(2):210-214.
2. Belfort MA. Placenta accreta. Am J Obstet Gynecol. 2010;203(5): 430-439.

3. Jauniaux E, Collins SL, Jurkovic D, Burton GJ. Accreta placentation: a systematic review of prenatal ultrasound imaging and grading of villous invasiveness. Am J Obstet Gynecol. 2016;215(6):712-721.

4. Wong HS, Cheung YK, Zuccollo J, Tait J, Pringle KC. Evaluation of sonographic diagnostic criteria for placenta accreta. J Clin Ultrasound. 2008;36(9):551-559.

5. Cali G, Giambanco L, Puccio G, Forlani F. Morbidly adherent placenta: evaluation of ultrasound diagnostic criteria and differentiation of placenta accreta from percreta. Ultrasound Obstetr Gynecol. 2013;41(4): 406-412.

6. Lerner JP, Deane S, Timor-Tritsch IE. Characterization of placenta accreta using transvaginal sonography and color Doppler imaging. Ultrasound Obstetr Gynecol. 1995;5(3):198-201.

7. Levine D, Hulka CA, Ludmir J, Li W, Edelman RR. Placenta accreta: evaluation with color Doppler US, power Doppler US, and MR imaging. Radiology. 1997;205(3):773-776.

8. Comstock CH, Love JJ Jr, Bronsteen RA, et al. Sonographic detection of placenta accreta in the second and third trimesters of pregnancy. Am J Obstet Gynecol. 2004;190(4):1135-1140.

9. Yang JI, Lim YK, Kim HS, Chang KH, Lee JP, Ryu HS. Sonographic findings of placental lacunae and the prediction of adherent placenta in women with placenta previa totalis and prior cesarean section. Ultrasound Obstetr Gynecol. 2006;28(2):178-182.

10. Palacios Jaraquemada JM, Bruno $\mathrm{CH}$. Magnetic resonance imaging in 300 cases of placenta accreta: surgical correlation of new findings. Acta Obstet Gynecol Scand. 2005;84(8):716-724.

11. Thompson MO, Otigbah C, Kelkar A, Coker A, Pankhania A, Kapoor S. The Management of Placenta Accreta at Queen's hospital, Romford, UK. In: Arulkumaran S, Karoshi M, Keith LG, Lalonde AB, B-Lynch C, eds. A Comprehensive Textbook of Postpartum Hemorrhage : An Essential Clinical Reference for Effective Management. 2nd ed. Dumfriesshire, Scotland: Sapiens Publishing; 2012:249.

12. Rac MW, Dashe JS, Wells CE, Moschos E, Mclntire DD, Twickler DM. Ultrasound predictors of placental invasion: the placenta Accreta index. Am J Obstet Gynecol. 2015;212(3):343.e341-343.e347.

13. Cali G, D'Antonio F, Forlani F, Timor-Tritsch IE, Palacios-Jaraquemada JM. Ultrasound detection of bladder-uterovaginal anastomoses in morbidly adherent placenta. Fetal Diagn Ther. 2017;41(3):239-240.

14. Dall'Asta A, Paramasivam G, Lees CC. Crystal Vue technique for imaging fetal spine and ribs. Ultrasound Obstetr Gynecol. 2016;47(3): 383-384.

How to cite this article: Aryananda RA, Akbar A, Wardhana MP, et al. New three-dimensional/four-dimensional volume rendering imaging software for detecting the abnormally invasive placenta. J Clin Ultrasound. 2018;1-5. https:// doi.org/10.1002/jcu.22641 